Special issue of the 2nd International Conference on Computational and Experimental Science and Engineering (ICCESEN 2015)

\title{
Preparation and Swelling Properties of Zeolite-Poly(2-hydroxyethyl methacrylate-co-acrylic acid) Hydrogel Composites
}

\author{
F. AKTI* AND F. BORAN \\ Hitit University, Chemical Engineering Department, Corum, Turkey
}

\begin{abstract}
Zeolite-Poly(2-hydroxyethyl methacrylate (HEMA)-co-acrylic acid (AA)) hydrogel composite materials were synthesized by in situ free radical addition polymerization technique. The swelling values obtained highly for the hydrogel are synthesized at HEMA/AA monomer ratio value of $80 / 20$. The hydrogel composites synthesized with zeolite having $-90 \mu \mathrm{m}$ particle size and $20 \mathrm{wt} \%$ amount showed the highest swelling degree. Zeolite adding to the hydrogel structure increased the swelling values of hydrogel. Synthesized samples were characterized using a Fourier transform infrared spectrometer technique.
\end{abstract}

DOI: 10.12693/APhysPolA.130.147

PACS/topics: 81.05.Qk, 82.35.Lr

\section{Introduction}

Hydrogels are defined three-dimensional network of hydrophilic polymer capable of showing extensive swelling in water and are used as effective adsorbent for various applications, including drug delivery, removal of heavy metal ions and dye molecules from aqueous solutions, etc. Zeolites which have high surface area, absorption capability, active hydroxyl groups, chemical stability and low cost are highly porous hydrated alumina silicate materials having three-dimensional crystal structures. Incorporation of zeolites to hydrogel structure improves the comprehensive properties of hydrogel $[1,2]$. It has not encountered to the synthesis of zeolite hydrogel composite materials with the HEMA/AA monomers in the literature. In this study, the effect of different HEMA/AA monomer ratio, particle size and amount of zeolite on the swelling behaviour of the Poly(HEMA-co-AA) hydrogel was investigated to determine a suitable and optimal synthesis condition for many applications such as drug loading, the removal of heavy metals from aqueous solutions.

\section{Experimental}

Zeolite-Poly(HEMA-co-AA) hydrogel composite (ZHC) was prepared using in situ free radical addition polymerization technique [3] at room temperature and atmospheric pressure. Firstly, different amounts of HEMA/AA (100/0,80/20,20/80,0/100) and divinyl benzene ( $1 \%$ molar ratio of the total mixture) (Merck) were dissolved in deionized water. Then potassium per sulfate/potassium meta bisulfide (Sigma-Aldrich) ( $0.5 \%$ molar ratio of the total monomer concentration at equimolar quantities) and natural zeolite (Gördes,

\footnotetext{
*corresponding author; e-mail: filizakti@hitit.edu.tr
}

Turkey) with different particle size $(-45,-63,-90,-125$, and $-180 \mu \mathrm{m})$ and loading $(2,5,10$, and $20 \mathrm{wt} \%)$ was dissolved in deionized water and added to previously prepared monomer solution. The mixture waited at room temperature for $24 \mathrm{~h}$ and the synthesized hydrogel composite was treated with $4 \mathrm{M} \mathrm{NaOH}$ solution for $4 \mathrm{~h}$ in order to reach the $\mathrm{pH}$ value of 7 . The swollen product was dehydrated several times using ethanol and finally samples were dried at room temperature. The swelling properties of hydrogels were determined based on swelling degree $\left(\mathrm{SD}=\left(m_{s}-m_{d}\right) / m_{d}\right)$, equilibrium swelling degree $\left(\mathrm{ESD}=\left(m_{s}-m_{100}{ }^{\circ} \mathrm{C}\right) / m_{s}\right)$ and water retention capacity $\left(\mathrm{WR} \%=\left(m_{s} / m_{d s}\right) \times 100\right)$, where $m_{s}$ and $m_{d}$ represent the weights of swollen and dried hydrogel at room temperature, respectively. Also $m_{100}{ }^{\circ} \mathrm{C}$ and $m_{d s}$ are the weights of dried hydrogel at $100^{\circ} \mathrm{C}$ and deswollen hydrogel in $0.9 \mathrm{wt} \% \mathrm{NaCl}$ solution, respectively [4]. The synthesized samples were characterized using a FTIR spectroscopy (Fourier transform infrared spectrometer, Thermo Scientific, Nicholet IS10) technique in the range of $650-4000 \mathrm{~cm}^{-1}$ wavelength.

\section{Result and discussion}

The effects of monomer ratio, particle size and amount of zeolite on the swelling properties of hydrogel are given in Fig. 1 and results are listed in Table I. The results showed that hydrogel having $80 / 20$ molar ratio exhibited slightly higher swelling degree than hydrogel having $100 / 0$ molar ratio (Fig. 1a). The increase of the amount of AA was caused by a decay of hydrogel. So that, other hydrogels' swelling properties were not performed. The highest SD, WR\% and ESD values were obtained as 1.1, 54.25, and 89.29, respectively. The water absorption capacity of ZHC was increased with an increase of the particle size (Fig. 1d). The highest SD, WR\% and ESD values were obtained as $16.61,50.79$, and 99.05 at $-90 \mu \mathrm{m}$ particle size, respectively. 

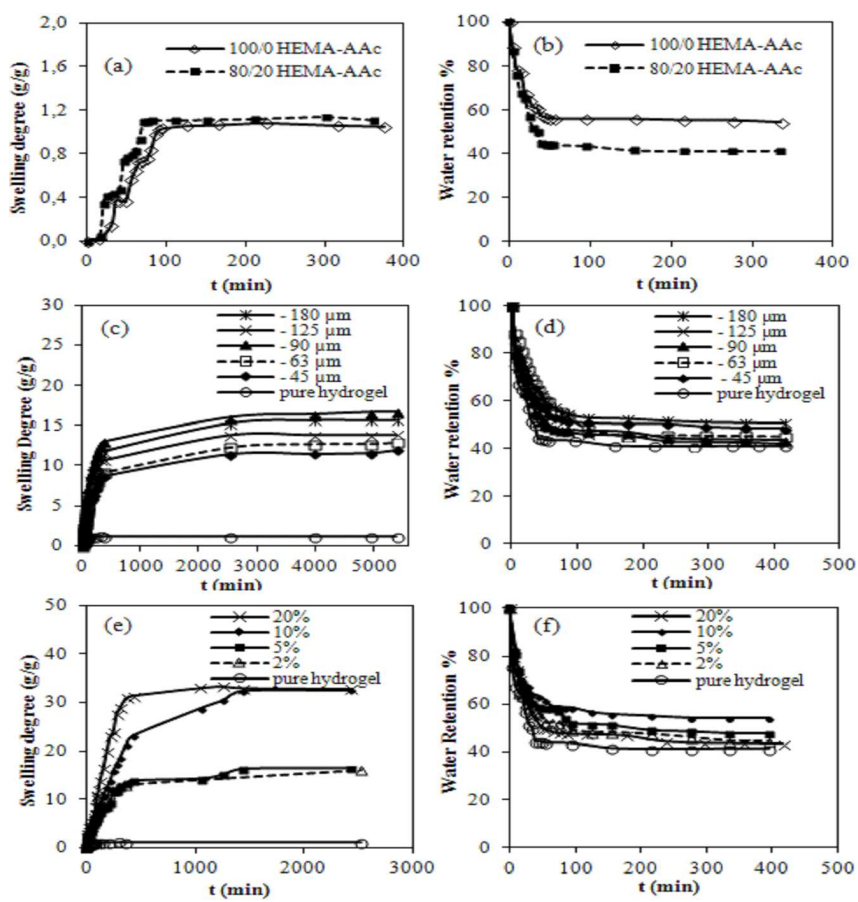

Fig. 1. The effect of monomer ratio (a, b); particle size $(c, d)$ and amount of zeolite $(e, f)$ on the swelling degree and water retention $\%$ of $\mathrm{ZHC}$.

It is also clearly seen that the $\mathrm{SD}$ value of $\mathrm{ZHC}$ was increased with increase of the amount of zeolite (Fig. 1e) and the SD, WR\% and ESD values reached 32.79, 54.02 and 98.58 by loading 20, 2, 5 wt\% zeolite, respectively (Table I).

FTIR spectra of hydrogel and ZHC are given in Fig. 2 . The bands observed at 3450, 2950, 1640, and $1162 \mathrm{~cm}^{-1}$

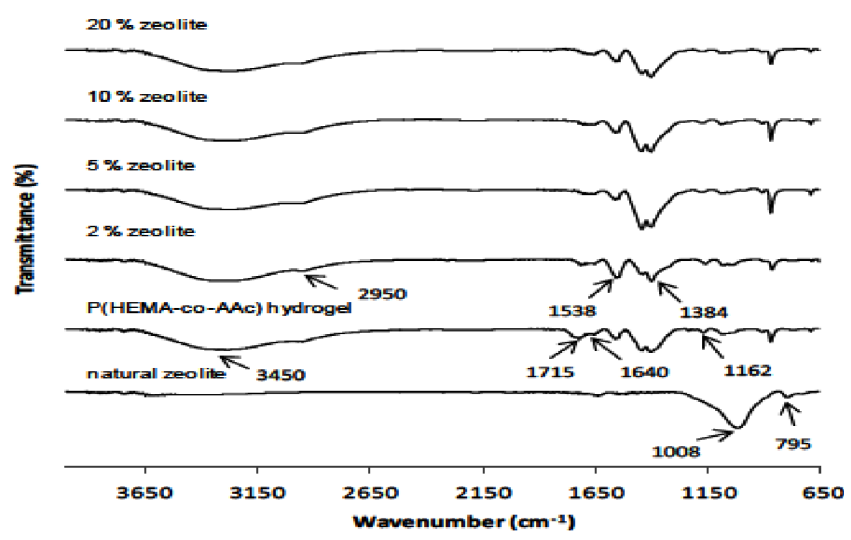

Fig. 2. FTIR spectra of zeolite, poly (HEMA-co-AA) hydrogel and ZHC.

were assigned to the characteristic peaks of HEMA corresponding to the stretching vibrations of $\mathrm{O}-\mathrm{H}, \mathrm{C}-\mathrm{H}$, $\mathrm{C}-\mathrm{C}$ and $\mathrm{C}-\mathrm{O}-\mathrm{C}$, respectively. These peaks appeared in the spectra of all ZHC. The peaks at 1715, 1538, and $1384 \mathrm{~cm}^{-1}$ represented the carbonyl groups and carboxylate ions of acrylic acid, respectively [5-7]. With the addition of zeolite to hydrogel, the peak at $1715 \mathrm{~cm}^{-1}$ was shifted slightly to lower wave number and also the intensity of peak at $1384 \mathrm{~cm}^{-1}$ was increased.

The peak appearing at $795 \mathrm{~cm}^{-1}$ corresponds to the asymmetric stretching vibrations of $\mathrm{T}-\mathrm{O}$ ( $\mathrm{T}$ : $\mathrm{Si}$ or $\mathrm{Al}$ ). The observed band at $1008 \mathrm{~cm}^{-1}(\mathrm{~T}-\mathrm{O}-\mathrm{T})$ is due to asymmetric stretching vibrations of tetrahedral $\mathrm{SiO}_{4}$ or $\mathrm{AlO}_{4}$ internal linkages in zeolite lattices [2]. The absence of these peaks in the FTIR spectrum of ZHC was attributed to the formation of crosslinking at these bands region [8].

The swelling properties of hydrogel and ZHC.

\begin{tabular}{|c|c|c|c|c|c|c|c|c|c|c|c|c|}
\hline \multirow{2}{*}{$\begin{array}{l}\text { Swelling } \\
\text { properties }\end{array}$} & \multicolumn{2}{|c|}{$\begin{array}{c}\mathrm{HEMA} / \mathrm{AA} \\
\text { molar ratios [\%] }\end{array}$} & \multicolumn{5}{|c|}{$\begin{array}{c}\text { Zeolite particle size }[\mu \mathrm{m}] \\
\text { (at } 80 / 20 \text { monomer ratio, } 2 \mathrm{wt} \% \text { ) }\end{array}$} & \multicolumn{5}{|c|}{$\begin{array}{l}\text { The amount of zeolite [wt\%] } \\
\text { (at }-90 \mu \mathrm{m})\end{array}$} \\
\hline & $100 / 0$ & $80 / 20$ & -45 & -63 & -90 & -125 & -180 & 0 & 2 & 5 & 10 & 20 \\
\hline SD & 1.05 & 1.11 & 11.83 & 12.81 & 16.61 & 13.84 & 15.61 & 1.11 & 16.61 & 16.34 & 32.52 & 32.79 \\
\hline $\mathrm{WR}(\%)$ & 54.25 & 41.25 & 48.61 & 45.24 & 43.43 & 42.05 & 50.79 & 41.25 & 43.43 & 54.02 & 47.66 & 44.40 \\
\hline ESD & 88.16 & 89.29 & 98.94 & 98.90 & 98.58 & 99.05 & 98.16 & 89.29 & 98.58 & 96.18 & 97.92 & 97.86 \\
\hline
\end{tabular}

\section{Conclusion}

The increase of amount of AA affected very little the swelling behavior of hydrogel. The adding of zeolite into the hydrogel structure improved the swelling properties of hydrogel. The swelling behavior of ZHC increased with increase of the amount of zeolite and maximum swelling degree was observed in composite with 20 wt\% zeolite. But, the particle size of zeolite did not show a regular effect on the swelling behavior. The FTIR spectroscopy results indicate that zeolite was successfully added to the hydrogel structure.

\section{References}

[1] Y. Zheng, Y. Zhu, A. Wang, Chem. Eng. J. 257, 66 (2014).

[2] V.V. Panic, S.J. Velickovic, Separat. Purific. Technol. 122, 384 (2014). 
[3] F. Boran, F. Akti, Hittite J. Sci. Eng. 2, 173 (2015).

[4] J. Liua, Q. Lia, Y. Sua, Q. Yue, B. Gao, Carbohydrate Polym. 107, 232 (2014).

[5] B. Gao, H. Hu, J. Guo, Y. Li, Coll. Surf. B Biointerf. 77, 206 (2010).

[6] H. Mahmoodian, O. Moradi, B. Shariatzadeha, T.A. Salehf, I. Tyagi, A. Maity, M. Asif, V.K. Gupta, J. Mol. Liq. 202, 189 (2015).
[7] M. Zendehdel, A. Zendehnam, F. Hoseini, M. Azarkish, Polym. Bull. 72, 1281 (2015).

[8] Y. Huang, M. Zeng, J. Ren, J. Wang, L. Fan, Q. Xu, Coll. Surf. A Physicochem. Eng. Asp. 401, 97 (2012). 